\title{
Glacial allopatry vs. postglacial parapatry and peripatry: the case of hedgehogs
}

\author{
Barbora Černa Bolfíková Corresp., ${ }^{1}$ ， Kristýna Eliášová ${ }^{2,3}$, Miroslava Loudová ${ }^{2}$, Boris Kryštufek ${ }^{4}$, Petros \\ Lymberakis ${ }^{5}$, Attila D. Sándor ${ }^{6}$, Pavel Hulva ${ }^{2,7}$ \\ ${ }^{1}$ Faculty of Tropical AgriSciences, Czech University of Life Sciences Prague, Prague, Czech Republic \\ 2 Faculty of Science, Charles University in Prague, Prague, Czech Republic \\ 3 Department of Zoology, National Museum, Prague, Czech Republic \\ 4 Slovenian Museum of Natural History, Ljubljana, Slovenia \\ 5 Natural History Museum of Crete, University of Crete, Heraklion, Greece \\ 6 Faculty of Veterinary Medicine, University of Agricultural Sciences and Veterinary Medicine Cluj-Napoca, Cluj-Napoca, Romania \\ 7 Faculty of Science, University of Ostrava, Ostrava, Czech Republic \\ Corresponding Author: Barbora Černa Bolfíková \\ Email address: bolfikova@ftz.czu.cz
}

Although hedgehogs are well-known examples of postglacial recolonisation, the specific processes that shape their population structures have not been examined by detailed sampling and fast-evolving genetic markers in combination with model based clustering methods. This study aims to analyse the impacts of isolation within glacial refugia and of postglacial expansion on the population structure of the Northern White-breasted hedgehog (Erinaceus roumanicus). It also discusses the role of the processes at edges of species distribution in its evolutionary history. The maternally inherited mitochondrial control region and the bi-parentally inherited nuclear microsatellites were used to examine samples within the Central Europe, Balkan Peninsula and adjacent islands. Bayesian coalescent inference and neutrality tests proposed a recent increase in the population size. The most pronounced pattern of population structure involved differentiation of the insular populations in the Mediterranean Sea and population within contact zone with $E$. europaeus in Central Europe. An inter-species hybrid was detected for the first time in Central Europe. A low genetic diversity was observed in Crete, while the highest genetic distances among individuals were found in Romania. Recent population in post-refugial area related to Balkan Peninsula shows a complex pattern with pronounced subpopulations located mainly in the Pannonian basin and at the Adriatic and Pontic coasts. Detailed analyses indicate that parapatry and peripatry may not be the only factors that limit range expansion, but also strong microevolutionary forces that may change the genetic structure of the species. Here we present evidence showing that population differentiation may occur not only during the glacial restriction of the range into the refugia, but also during the interglacial range expansion. Population differentiation at Balkan Peninsula and 
adjacent regions could be ascribed to diversification in steppe / forest biomes and complicated geomorphology, including pronounced geographic barriers as Carpathians. 


\section{Glacial allopatry vs. postglacial parapatry and peripatry: the case of hedgehogs}

Barbora Černá Bolfíková (1, §), Kristýna Eliášová (2,3*), Miroslava Loudová (2), Boris Kryštufek (4), Petros Lymberakis (5), Attila D. Sándor (6), Pavel Hulva (2,7)

(1) Faculty of Tropical AgriSciences, Czech University of Life Sciences Prague, Prague, Czech Republic

(2) Faculty of Science, Charles University in Prague, Prague, Czech Republic

(3) Department of Zoology, National Museum, Prague, Czech Republic

(4) Slovenian Museum of Natural History, Ljubljana, Slovenia

(5) Natural History Museum of Crete, University of Crete, Heraklion Crete, Greece

(6) Faculty of Veterinary Medicine, University of Agricultural Sciences and Veterinary Medicine Cluj-Napoca, Cluj-Napoca, Romania

(7) Faculty of Science, University of Ostrava, Ostrava, Czech Republic

$\S$ corresponding author

Barbora Černá Bolfíková

Faculty of Tropical AgriSciences, Czech University of Life Sciences Prague,

Kamýcká 129

16521 Prague

Czech Republic

Email: bolfikova@ftz.czu.cz

Tel. 00420224382497

Fax. 00420224382497 


\section{Abstract}

3 Although hedgehogs are well-known examples of postglacial recolonisation, the specific

4 processes that shape their population structures have not been examined by detailed sampling

5 and fast-evolving genetic markers in combination with model based clustering methods. This

6 study aims to analyse the impacts of isolation within glacial refugia and of postglacial expansion

7 on the population structure of the Northern White-breasted hedgehog (Erinaceus roumanicus). It

8 also discusses the role of the processes at edges of species distribution in its evolutionary history.

9 The maternally inherited mitochondrial control region and the bi-parentally inherited nuclear microsatellites were used to examine samples within the Central Europe, Balkan Peninsula and adjacent islands. Bayesian coalescent inference and neutrality tests proposed a recent increase in the population size. The most pronounced pattern of population structure involved differentiation of the insular populations in the Mediterranean Sea and population within contact zone with $E$. europaeus in Central Europe. An inter-species hybrid was detected for the first time in Central Europe. A low genetic diversity was observed in Crete, while the highest genetic distances among individuals were found in Romania. Recent population in post-refugial area related to

17 Balkan Peninsula shows a complex pattern with pronounced subpopulations located mainly in the Pannonian basin and at the Adriatic and Pontic coasts. Detailed analyses indicate that

19 parapatry and peripatry may not be the only factors that limit range expansion, but also strong microevolutionary forces that may change the genetic structure of the species. Here we present

21 evidence showing that population differentiation may occur not only during the glacial restriction

22 of the range into the refugia, but also during the interglacial range expansion. Population

23 differentiation at Balkan Peninsula and adjacent regions could be ascribed to diversification in 
24 steppe / forest biomes and complicated geomorphology, including pronounced geographic

25 barriers as Carpathians.

\section{Background}

Consequences of geographic isolation and gene flow limitation are highly debated topics in biogeography (Coyne \& Orr, 2004). Strong empirical evidence for the role of isolation in different modes of speciation has been obtained by analysis of temperate species that underwent episodes of refugial isolations in the Mediterranean region during the Pleistocene climate oscillations (Hewitt, 2000). Balkan Peninsula acted as one of the main glacial refugium for European biota (Hewitt, 2000) and is considered as an important source of endemism and genetic diversity due to its position, historical development, topography and climatic variability (Kryštufek \& Reed, 2004). After the Last Glacial Maximum (LGM), many species expanded from this area northward (Hewitt, 2000). Range expansion may be limited not just by various abiotical factors, but also by formation of a contact zone and parapatry with a related species. Interspecies interactions may lead to quick reinforcement, i.e. evolution of adaptations preventing formation of hybrids. Terrestrial taxa whose ranges are restricted by the sea barrier may colonise particular islands, providing an opportunity for peripatric evolution which is characterised by a strong founder effect, genetic drift and other island phenomena.

Hedgehogs from the Erinaceus genus are a classical example of postglacial recolonisation of the Western Palearctic (Hewitt, 2000). Recently, we recognize three species occupying this area. Northern White-breasted hedgehog (Erinaceus roumanicus Barrett-Hamilton, 1900) currently inhabits Central and Eastern Europe, the Baltic, and the Balkan Peninsula, and its eastern range stretches to western Siberia. The current data indicate that the Balkan Peninsula used to be the only refugium for E. roumanicus (Seddon et al., 2001; Hewitt, 2001). The Caucasus Mountains 
47 and the Bosporus strait currently form a barrier between E. roumanicus and its sister species

48 Southern White-breasted hedgehog (E. concolor Martin, 1837), which inhabits Asia Minor. It

49 has been estimated that these two species diverged approximately $0.4-1.4$ million years ago

50 (Bannikova et al., 2014). Western Europe and Scandinavia are populated by Western European

51 hedgehog (E. europaeus Linne 1758) whose refugial area used to exist in the Iberian and

52 Apennine Peninsulas. After the LGM, hedgehog species expanded from the southern refugial

53 areas and created contact zones in the Baltics and in Central Europe (Seddon et al., 2001;

54 Santucci, Emerson \& Hewitt, 1998). Central European contact zone was probably established

55 during the Neolithic deforestation and occurrence of interspecies hybridization is probably rare

56 or absent (Bolfíková \& Hulva, 2012). On the other hand one hybrid individual was reported from

57 Baltic contact zone and the authors speculate that hybridization must be common in this area

58 (Bogdanov et al., 2009). Seddon et al. (2001) suggest the presence of at least three mitochondrial

59 lineages of E. roumanicus. The first lineage, which previously expanded from the Balkans to

60 Russia and Ukraine, colonises the northern foothills of the Caucasus Mountains. The second

61 lineage colonises western parts of Europe, and the third lineage is present in Greece.

62 A large morphologic variability has been observed for E. roumanicus throughout its wide population range, and multiple subspecies have been described. A study has recently proved that body size variability is strongly associated with the environment, and it clinally varies in the mainland (Kryštufek et al., 2009). A morphometric study by Kryštufek et al. (2009) revealed a positive correlation between body size and temperature and a negative correlation between body

67 size and summer precipitation. Association between particular species and their habitats give rise to the need of comparative phylogeographic studies. Dependency of Erinaceus hedgehogs on deciduous woodland (Rautio 
70

71

72

et al., 2014; Jensen, 2004) is in concordance with similar phylogeography observed in Oak and Silver Fir (Hewitt, 2000; Seddon et al., 2001) and implies that the extension of forests was followed by the hedgehogs. Some literature highlights an E. roumanicus preference for lowlands and open landscapes, particularly during the spatial expansion (Bolfíková \& Hulva, 2012; Seddon et al., 2002). However, modern studies based on past environmental niche modelling are missing. Moreover, ecological considerations are based rather on knowledge of Erinaceus europaeus, while data on E. roumanicus are scarce. Different position of these two species ranges on often overlooked oceanic-continental axis, represented by more humid and less seasonal climate on the west and the opposite in the east, should be also considered (Stewart et al., 2010). The southern parts of E. roumanicus range are located mainly in drier biomes in the Mediterranean basin and Pontic-Caspian steppe. Northern parts of the range are situated mainly in the temperate deciduous forests. Adaptations to the more dry open and seasonal habitats in $E$. roumanicus could not be excluded (Bolfíková \& Hulva, 2012).

Do the classical models have a potential to further develop phylogeogeographic paradigm using up to date tools of the landscape genetics? Here, we provide new information on the hedgehog's evolutionary history using a combination of fast evolving markers, including nuclear microsatellites and mitochondrial control region. By analysing multiple E. roumanicus samples ranging from the post-refugial area in the Balkan Peninsula to the parapatric contact zone with $E$. europaeus in central Europe, we aim to:

1) assess the population structure of E. roumanicus within the studied area using the spatial and non-spatial Bayesian clustering methods and discuss observed patterns within landscape genetic framework in the light of geomorphology and habitat quality of the region; 
92 2) reveal the history of island populations and suggest possible way of colonisation of these

93 islands. He hypothesize, that insular effects like founder effect, genetic drift and other factors

94 which decrease genetic variation highly affected these populations;

95 3) analyse the populations in the secondary contact zone from Central Europe. We hypothesize

96 that respective populations were affected by species interactions, including introgression and

97 reinforcement;

98 4) analyse the populations from the post-refugial areas at Balkan peninsula and assess the 99 hypothesis of occurrence of the glacial subrefugia.

\section{Material and Methods}

102

Sampling and genotyping

Samples obtained from muscle tissue or digits or ears were collected from road-killed animals or from museum collections. No special permit is needed from the Institutional Review Board. The tissues were fixed in $96 \%$ ethanol and stored at $-20{ }^{\circ} \mathrm{C}$. The samples were obtained in cooperation with the Natural History Museum of Crete (Petros Lymberakis), the Slovenian Museum of Natural History (Boris Kryštufek), and the University of Agricultural Sciences and Veterinary Medicine Cluj Napoca (Attila Sandor). For the study, 314 samples were analysed from the following European countries: Czech Republic (49), Slovakia (26), Hungary (9),

111 (6), Serbia (10), Bulgaria (4), Macedonia (17) and Greece (59), which included several islands 112 (the Ionian islands, Euboea, Cyclades, and Crete). Each sample's origin, GPS coordinates, and 113 date of collection along with the name of the person who collected it are listed in Supplemental 
114 information: Table S1. A map (Fig. 1), indicating the geographic origins of the samples, was

115 created using Geographic Information System (ESRI, 2014).

116 DNA was extracted using a commercial DNA Blood and Tissue Kit (Qiagen, Hilden, Germany).

117 A combination of nine microsatellite markers and mtDNA control region sequences was used.

118 Laboratory procedures were performed according to the protocols by Bolfíková \& Hulva (2012),

119 details may be found in Supplemental information: Table S3. Each dataset was analysed 120 separately as specified below.

121

122 Non-spatial analyses of genetic variability

123 The sizes of the microsatellite alleles were determined using GeneMarker V1.85

124 (www.softgenetics.com). Data binning was performed with the AutoBin software

125 (http://www4.bordeauxaquitaine.inra.fr/biogeco/layout/set/print/Ressources/Logiciels/Autobin).

126 The presence of the null alleles (false homozygotes), stutter bands and large allele dropouts was

127 tested using Micro-Checker (Van Oosterhout et al., 2004). Bayesian statistics for recognising

128 hybrid categories was run in NewHybrids 1.1 (Anderson \& Thompson, 2002).

129 Evaluation of the genetic structuring of the microsatellite dataset was performed with a Bayesian

130 Clustering Analysis in Structure 2.2 (Pritchard, Stephens \& Donnely, 2000). Structure

131 determines the most likely assignment of individuals to clusters $(K)$ based on analysis of

132 likelihood. Structure is powerful to detect clinal variability and high geographic admixture in the 133 dataset (Chen et al., 2007). The parameters of the final run were as follows: $1000000 \mathrm{MCMC}$ 134 steps, with burn-in-period 100000 and 5 iterations for each $K$. An Admixture Model of 135 Correlated Frequencies was used. The number of tested population was within the $K=1-14$ 136 interval. The results of the analyses were combined and evaluated by Structure Harvester (Earl \& 
137 VonHoldt, 2012) using the Evanno method (Evanno, Regnaut \& Goudet, 2005). Graphic

138 visualisation was provided using Distruct 1.1 (Rosenberg, 2004). The inbreeding coefficient $\left(F_{\text {IS }}\right)$

139 for each population was tested by GenePop (Rousset, 2008). Departures from the Hardy-

140 Weinberg equilibrium $(H W E)$, number of alleles $\left(N_{\mathrm{a}}\right)$ and allelic richness $\left(A_{\mathrm{R}}\right)$ were estimated in

141 FSTAT (Goudet, 1995). Allelic richness was used to estimate an allele numbers, across all loci,

142 corrected for equal sample size in all analysed populations. The population with the smallest

143 number of individuals was $N=24$ from Crete. The expected $\left(H_{\mathrm{E}}\right)$ and observed $\left(H_{\mathrm{O}}\right)$

144 heterozygosities were computed using Genetix (Belkhir et al., 1999).

145 Sequences of the mtDNA partial control region were edited using Geneious (Kearse et al., 2012)

146 and aligned using MAFFT (Katoh \& Standley, 2013). Particular haplotypes were identified in

147 DnaSP v.5 (Rozas et al., 2003). The haplotype data were submitted to GenBank ${ }^{\circledR}$ (Accession

148 numbers are from KY489901 to KY489953). The relationships among the haplotypes were

149 visualised by the median-joining network (Bandelt, Forster \& Röhl, 1999) using Network 4.5

150 (www.fluxus-engineering.com). The demographic parameters were estimated by summary

151 statistics of the genetic variability for each population (recognised by the Bayesian clustering

152 analysis of the haplotype data using the Geneland software; details in spatial analyses below).

153 Tests for haplotype diversity ( $h$; represents the probability that two randomly chosen haplotypes

154 are different), nucleotide diversity ( $\pi$; the average number of nucleotide substitutions per site

155 between two sequences) and neutrality tests (Tajima's $D$, Fu's $F_{\mathrm{S}}$ and $R^{2}$ ) were computed for each

156 population in DnaSP v.5 (Rozas et al., 2003). Fu's $F_{\mathrm{S}}$ (for big sample sizes) and $R^{2}$ (for small

157 sample sizes) are considered as the most powerful tests (Ramos-Onsins \& Rozas, 2002, Ramírez-

158 Soriano et al., 2008). Significantly negative results indicate presence of selective sweep or strong

159 population growth signal in the data. The course of the past population size was estimated with 
160 coalescent-based Bayesian skyline plots (Drummond et al., 2005). We inferred the model of

161 sequence evolution in jModelTest (Posada \& Crandall, 1998) using Bayesian information

162 criterion (BIC). The Bayesian skyline plot analysis was conducted using the BEAST 1.4.8

163 program (Drummond \& Rambaut, 2007) with a strict molecular clock and a GTR+I+G

164 substitution model. The MCMC procedure was run three times for each species with 30000000

165 iterations, and the genealogy and parameters of the model were stored every 1000 iterations.

166 The results were combined in LogCombiner, and burn-in was set to 10000000 iterations in each

167 run. The Bayesian skyline plot and the convergence of chains were assessed by Tracer v.1.4

168 (Rambaut et al., 2014).

Spatial analyses of genetic variability

171 To analyse the spatial genetic architecture of E. roumanicus in the area of interest, we used two 172 spatial model based clustering approaches, including software Geneland 4.0.4 (Guillot, Mortier 173 \& Estoup, 2005) and TESS (Chen et al., 2007; Durand et al., 2009). Geneland encompasses 174 Bayesian clustering of individual genotypes based on separation of random mating 175 subpopulations and produces Dirichlet cells centred on subpopulation territories. Geneland can 176 analyse both haplotype data and codominant data in independent runs. The parameters for the 177 Geneland analysis were set for each marker type as follows: $500000 \mathrm{MCMC}$ iterations, thinning $178=100$, five independent runs and $\mathrm{K}=1-15$. The posterior probability of the subpopulation 179 membership for the most supported run was computed for each pixel of the spatial domain, using 180 a burn-in of 50 iterations. An uncorrelated Frequency Model was chosen. TESS is based on 181 minimizing of Wahlund effect and produces Dirichlet cells based on individuals and is using 182 microsatellite data. We chose BYM model due to lower Deviance Information Criterion (DIC) 
183 and higher stability of algorithm. The first run of program was set to Kmax $=2$ - 10 populations,

184 then we plotted Kmax versus DIC values and selected the optimal Kmax (see details in

185 Supplemental information: Figure S1). The final run of TESS was set to Kmax = 5 - 6, with 50

186000 sweeps, a burn-in 30000 , the interaction parameter $\Psi=0.6$ and 100 iteration for each $\mathrm{K}$. The

187 lowest DIC values were performed for $\operatorname{Kmax}=6$ and we chose as representative the run within

$18830 \%$ of runs with lowest DIC values, displaying five colours.

189 Combination of these approaches may be useful in exploring spatial population structure

190 (Balkenhol et al., 2015), as Geneland performs well in detecting recent linear barriers to gene 191 flow (Blair et al., 2012), while TESS addresses situations with barriers of complex shapes and

192 permeability for migrants, as well as secondary fusions of subpopulations (Chen et al., 2007).

193 The Mantel test (Mantel, 1967) was used to characterise the presence of isolation-by-distance to 194 evaluate the correlation between congruent similarity/dissimilarity matrices, which addressed the 195 relationship between the geographic and genetic distances of observations across a landscape 196 provided by the Alleles in Space (AIS) software (Miller, 2005). The number of iterations used 197 was 1 000. We used the AIS software for the Genetic Landscape Shape Analysis to compute the 198 genetic distances, which were assigned to the connector centres of each locality using 199 Delauney's triangulation. The interpolation procedure, which determined the presumed genetic 200 distances in a lattice frame containing 15-km units, covered the area of interest, and a graph of 201 the interpolated distances was created. Peaks in this graph represent an area of high genetic 202 distances and should be correlated with areas of restricted gene flow. Both marker types were 203 independently analysed using AIS software. 


\section{Results}

206 We did not detect any genotyping errors that resulted from a large allele dropout or stutter bands

207 in 260 samples that were successfully genotyped at nuclear markers. All genotyped individuals

208 are indicated in Supplemental information: Table S1. Micro-Checker detected null alleles in

209 several microsatellite loci, and the estimated frequencies differed between loci and populations.

210 The estimated frequencies were lower than 0.2432 for all populations examined. In the Cretan

211 population, two loci, EEU12H (0.2432) and EEU3 (0.2099), showed high null allele frequencies

212 using the methods described by Van Oosterhout et al. (2004). Primers were designed for $E$.

213 europaeus (Becher \& Griffiths, 1997; Henderson et al., 2000) and tested by Bolfíkova \& Hulva

214 (2012). All genotypes were originally obtained from the tissues, which are less susceptible to the

215 presence of null alleles than non-invasive samples. Further analyses proved that the Cretan

216 population was influenced by the founder effect, genetic drift and inbreeding. Thus, the null

217 allele estimation was probably influenced by the high homozygote frequency in the population.

218 Sequences produced by Sanger sequencing were of good quality and some individuals with

219 ambiguous sites were re-sequenced or skipped from the analyses. A total of 296 partial control

220 region sequences $(404 \mathrm{bp})$ were obtained and represented 53 haplotypes among the analysed

221 samples (see details in Supplemental information: Table S1).

222

\section{Non-spatial analyses of genetic variability}

224 The nine selected microsatellite loci were polymorphic. The total number of alleles in a single

225 locus varied from 5 to 23 for the entire dataset. One sample from the Slovakia (Trencianske

226 Teplice) was omitted from further analysis because it was suspected of having a hybrid origin. A

227 follow-up analysis with the NewHybrids program (Anderson \& Thompson, 2002) using the 
228 original dataset from Bolfíková \& Hulva (2012) confirmed that the sample was a backcrossed

229 hybrid of E. europaeus and E. roumanicus; the mitochondrial DNA originated from $E$.

230 roumanicus.

231 From the total number of tested clusters $(K=1-14)$, division into the three populations $(K=3)$

232 obtained the highest support according to Evanno et al. (2005). The populations were

233 differentiated as follows: (i) samples from Crete and from the Hellenic peninsula in southern

234 Greece; (ii) samples from the Balkan area (Serbia, Bulgaria, Macedonia, Greece, Montenegro,

235 Croatia and Bosnia and Herzegovina) plus Slovenia and Romania; and (iii) samples from Central

236 Europe (Czech Republic, Slovak Republic and Hungary) (Fig. 2a). The second highest $\Delta K$ value

237 was observed for a division into the seven populations $(K=7)$. An increasing number of clusters

238 resulted in further differentiation of the Balkan population by separation of the population from

239 Pannonia (at $K=4$ ), differentiation of the Slovenian population $(K=5)$ and separation of

240 populations from the west and east of the Balkans (from $K=6$ ). However, there is certain degree

241 of admixture among particular clusters. Two different landscape genetic algorithms supported

242 similar spatial pattern with three (Geneland, Fig. 5d) and five (TESS, Fig. 2b) clusters.

243 The aforementioned differentiation was also tested without the Czech and Slovakian samples,

244 whose genetic architecture could have been influenced by phenomena associated with the

245 recently developed contact zone. This analysis of Structure supported the previous subdivision of

246 our dataset.

247 The genetic variability parameters are given for the seven populations (Table 1) and three 248 populations (Supplemental information: Table S2). $H_{\mathrm{O}}$ was significantly lower than $H_{\mathrm{E}}$ and

249 GenePop analyses showed a significant lack of heterozygotes $(\mathrm{p}<0.01)$ for each population.

250 Crete had lowest $A_{\mathrm{R}}$ and $H_{\mathrm{E}}$. Highest $F_{\mathrm{IS}}$ was detected in Romanian population. 
251 The median-joining network didn't demonstrate reciprocally monophyletic lineages in the

252 studied area (Fig. 3). Haplotypes are shared across populations, but some trends are visible. One

253 unique haplotype shared with majority of individuals from Crete and few other haplotypes

254 carried by one or two individuals are representing population of South Balkan (in blue on Fig. 3).

255 Similar pattern is representing Central Europe (in orange on Fig. 3). North Balkan population (in

256 pink on Fig. 3) has two locally common haplotypes, but individuals from Central Europe and

257 Dinaric area are also sharing them. Carpathian population (in yellow on Fig. 3) had several

258 haplotypes in common with other populations but also several unique haplotypes. Samples from

259 Dinaric area (in green on Fig. 3) were wide-spread in the network and produced star-like pattern

260 around haplotype that is common in Slovenia, Hungary and Croatia. Black sea coast population

261 (in violet on Fig. 3) has several unique haplotypes which are widespread within the network.

262 The genetic variability parameters for mitochondrial data were estimated for six populations

263 according to the results of analysis in Geneland (Table 2). All tests of neutrality yielded negative

264 values indicating recent population growth, only Central European (containing Czech Republic,

265 East Slovakia and North Hungary) population neutrality tests were not significant (Table 2). The

266 Bayesian skyline plot indicated a long period with a stable population size and its recent increase

267 (Fig. 4.).

268

269

Spatial analyses of genetic variability

270 The Mantel test indicated a significant isolation by distance $(\mathrm{r}=0.303 ; \mathrm{p}<0.001)$ within our

271 dataset. Geneland analysis of microsatellite markers determined that the division of our dataset

272 into three populations (Central Europe, mainland area, and south Greece plus islands) was the

273 most likely to occur (Fig. 5d). Analysis implemented by TESS revealed the most fitting Kmax= 
274 6, which spatially represents five clusters corresponding to population from Crete, Czech

275 Republic, Pannonian area, Eastern and Western part of Balkan Peninsula (Fig. 2b). This pattern

276 is in concordance with results of Structure analysis for $K=5$ (Fig. 2a). Mitochondrial analysis

277 divided our dataset into the following six clusters: (i) South Balkan (southern and central Greece,

278 Peloponnese, Crete and the adjacent islands); (ii) Dinaric area (north Greece, Macedonia, south

279 Bosnia and Hercegovina, south Croatia, Montenegro and south Serbia); (iii) Black sea coast

280 (Thrace and most of Bulgaria and southeast Romania); (iv) Carpathian area (northwest Romania,

281 east Slovak Republic and east Hungary); (v) North Balkan (north Serbia, north Bosnia and

282 Herzegovina, north Croatia, Slovenia, southwest Hungary and north Italy); and (vi) Central

283 Europe (northwest Hungary, west Slovak Republic and Czech Republic) (Fig. 5c; Supplemental

284 information: Table S1). Genetic Landscape Shape Analysis using AIS software detected very

285 low genetic distances in Crete and the Czech Republic based on the mitochondrial data and

286 nuclear data in particular. However, high genetic distances were observed with the

287 microsatellites among samples in regions to the south and east of the Balkan Peninsula, with the

288 highest peaks observed in Romania (Fig. 5b). The mitochondrial data showed flat genetic 289 landscapes (Fig. 5a).

\section{Discussion}

292 Based on the results obtained using both non-spatial and spatial individual based clustering approaches, the population from the southernmost region of the range (including southern

294 Greece and the adjacent islands) and the population from the contact zone with E. europaeus were separated from the rest of the range. This pattern indicates that processes acting at peripatric and parapatric range edges shaped the genetic architecture of the species substantially. 
297 Further differentiation in clustering hierarchy provides evidence for occurrence of

298 subpopulations within southeast part of the range. This result could be ascribed to complicated

299 geomorphology and land cover of the region and may imply also subdivision of refugial

300 populations in the past.

301

302

Insular populations in the Mediterranean Sea

303

304

305

306

307

308

309

310

311

312

313

314

315

316

317

318

319

All analyses indicate strong differentiation of the individuals from Crete, Cyclades and from Peloponnese, Euboea and southern and central Greece. As the largest island of Greece and the fifth largest Mediterranean island, Crete is typified by impoverished native mammalian fauna and the high impact of recently introduced species. However, Crete is also known as a generator of novelty in the numerous lineages that were able to colonise the island. From a macroevolutionary viewpoint, Crete is the place where pygmy forms of deer, elephants and hippopotamuses occurred (Van der Geer et al., 2010). From the microevolutionary viewpoint, the cryptic bat species occur there (Hulva et al., 2007; Hulva et al., 2010). Peloponnesus is also typified by its cryptic variability in vertebrates (Gvoždík et al., 2010). The isolation of this region was recently enhanced by the 1893 construction of the Corinth Canal, which effectively separated Peloponnesus from the mainland. However, our analyses do not confirm a reciprocal monophyly for the E. r. nesiotes subspecies, which supports the findings by Schaschl, Lymberakis \& Suchentruck (2002). Moreover, we ascertain that in addition to Crete, the range of this population includes other islands and reaches continental Greece. The assessment of the geographic origins and dispersal scenarios of this population will require more detailed analysis. However, the presumably absent land bridge between Crete and the mainland during the Pleistocene period (Schule, 1993), the absence of hedgehogs in Crete's fossil record (Lax \& 
320 Strasser, 1992) and the frequent introductions of hedgehogs onto the islands by humans

321 (Bolfiková et al., 2013) indicate that the role of the anthropogenic factor in the phylogeography

322 of the southern cluster is highly probable.

323 The first archaeological evidence of hedgehogs in Crete was collected from an Early Minoan

324 tomb (Jarman, 1996), but the author concluded that the hedgehog might have been an intrusion

325 (e.g., entered the tomb much later). Using allozymes and partial cytochrome $b$ sequences,

326 Schaschl, Lymberakis \& Suchentruck (2002) proposed that hedgehogs were introduced to Crete

327 by archaic settlers from the mainland. This population was previously described as a subspecies, 328 E.r. nesiotes, by Dorotha Bate in 1906 based on phenotypic data. These facts imply the

329 occurrence of insular syndrome in the Cretan population. The markedly decreased genetic

330 variation values in the insular population imply that factors such as the founder effect and 331 genetic drift played substantial roles. The agreement between the genetic variation patterns and 332 the phenotypic data indicates that insular syndrome, including dwarfism in hedgehogs from the 333 Greek islands, has occurred (Kryštufek et al., 2009; Giagia-Athanasopoulou \& Markakis, 1996).

334 Despite the uncertainty surrounding the origins of differentiation for the southern cluster, the 335 aforementioned results indicate a pronounced role for peripatric processes in the microevolution 336 of E. roumanicus. Elevated evolutionary rates in islands are obvious also in phenotypic 337 evolution. The trends in body size changes of insular hedgehogs are negatively correlated with 338 the island's distance from the mainland, however, the insular response was not uniform 339 (Kryštufek et al., 2009).

341 Secondary contact zone with E. europeaus in Central Europe 
342 The population from Central Europe is genetically different from the rest of the mainland, as

343 suggested by all Bayesian clustering analyses. This cluster is also characterised by its lower

344 genetic variation, even though, in some parameters still comparable to post-refugial populations.

345 This may be the outcome of spatial expansion, which is usually followed by a decrease in genetic

346 variability due to the bottleneck effect. More complex phenomena, such as allele surfing

347 (increase of an allele frequency in the wave front of an expanding population), might alter the

348 genetic architecture of the population's expanding edge and change the genetic variation as well

349 (Klopfstein, Currat \& Excoffier, 2006; Excoffier \& Ray, 2008; Excoffier, Foll \& Petit, 2009).

350 Demographic analyses did not confirmed statistically significant population size increase. Thus,

351 we suspect that the aforementioned phenomena played important roles in shaping the population

352 genetics of Central European hedgehogs. Other factors that caused population differentiation in

353 this case may be associated with parapatry and its consequent species interactions. Ecological

354 interactions and their consequent selections may have influenced the diversity of the studied

355 microsatellite loci by genetic hitchhiking, while hybridisation and introgression in the secondary

356 contact zones may have further shaped the allopatrically evolved lineages and potentially cover

357 the signal of recent population expansion. These potential factors will require further study and

358 genomic tools.

359 We are the first to report a single hybrid sample from the range margins of E. europaeus in the

360 Central Europe (Slovakia - Trenčianske Teplice) using traditional genetic markers. Interspecies

361 interactions in the sympatry zone may have previously played roles in forming reproductive

362 barriers. We hypothesised that hybridisation occurred when the two species came into contact for

363 the first time, when the isolating mechanisms were not yet formed. Afterwards, during the

364 reinforcement phase, species developed mechanisms for reproductive isolation and the hybrid 
365 event frequency decreased for follow-up generations. The history of possible hybridisation

366 events in the Central European population should be tested using approaches that include whole

367 genome data because the introgression modes may be complex. Future investigations should

368 address the contact zone at the Slovenian/Italian border (located to the south of the Alps) and the

369 effect of altitudinal heterogeneity on both species. This region involves the contact zone for both

370 species and the transition zone between the Slovenian mountains and the Padan Plain.

371 The lower genetic diversity associated with the range margins and the novel selective pressures

372 applied by interactions with related species may be why the Central European population was

373 highly divergent from the other populations in the dataset.

Post-refugial areas at the Balkan Peninsula and adjacent regions

376

377

378

379

380

381

382

383

384

385

386

387

Separation of the Pannonian population represents the most pronounced pattern after the split of parapatric and peripatric populations. Pannonian basin is confined area from the view of geographical isolation by Carpathian arch and vegetation cover typical by grass steppe, i.e. possess habitat similarity with the part of species range in Pontic-Caspian steppe. Consequently, it represents pronounced biogeographical region of Europe and presumed continental interglacial refugium of continental and steppe faunal elements (Stewart et al., 2010, Říčanová et al., 2011). In E. roumanicus, this pattern might mirror geographical isolation, ecological differentiation, and also the quality of ancestral habitat and larger extent of steppe biome during glacial periods.

Further differentiation occurs between populations from the west of the peninsula at the Adriatic coast and the east at Black sea coast. This differentiation might be ascribed to isolation by distance and barrier role of Carpathian Mountains. For example, based on the results provided by AIS, the largest genetic distances between the samples in our dataset are located in Romania. 
388 This pattern implies a restricted level of gene flow within the population, which might be 389 ascribed to the high altitudinal heterogeneity of the Carpathian Mountains. However, this pattern 390 may also mirror occurrence of forest refugia at Adriatic and Pontic regions. The Black Sea shore 391 likely served as a glacial refugium for multiple animal species, such as Bombina bombina 392 (Fijarczyk et al., 2011) and Emys orbicularis (Joger et al., 2007). The presence of trees during 393 the LGM has also been proven (Tzedakis, 2004). Palynological analyses have confirmed 394 occurrence of isolated forests within the refugia in response to climatic and spatial variabilities 395 (Huntley, 1999), for example in the Pindos Mountains in northwestern Greece, where levels of 396 precipitation were higher (Tzedakis, 2004). In the case of the European oak Quercus, two 397 separate Balkan subrefugia (Greece and the west coast of the Black Sea) have been located 398 (Brewer et al., 2002). King \& Ferris (1998) discovered unique haplotypes of the European alder 399 (Alnus glutinosa) in the regions around Bulgaria and Greece. Based on these examples, Tzedakis 400 (2004) presumed the existence of temperate forests during the last glacial maximum in the 401 mountainous and coastal areas, whereas two previously identified subrefugia occurred in western 402 Greece and in eastern Bulgaria near the Black Sea.

403 The population from Slovenia is separated from the Balkan genotypes in Structure analyses. This 404 pattern suggests a gene flow limitation due to the geographical isolation, caused by the Alps, the 405 Dinarids and/or specific climatic conditions. For example, a fully grown forest was present 406 during the LGM in Slovenia (Tzedakis, 2004). Another hypothesis suggests a possible species 407 interaction with E. europaeus and, consequently, a local parapatic evolutionary process (see 408 above).

409

410 Conclusions 
411 The most pronounced pattern within our dataset was represented by the differentiation of

412 populations at the edges of the recent range. This study indicates that peripatry and parapatry

413 might be not only limiting factors to range expansion, but may also provide strong

414 microevolutionary forces that shape the genetic structure of the species. Traditionally, population

415 differentiation in temperate species has been ascribed to allopatric processes during glacial

416 periods. Here, we provide an alternative example, showing that population differentiation may

417 occur not only during the glacial restriction of the range into refugia, but also during the phase of

418 interglacial range expansion. During the interglacial periods, peripatric modes of evolution for

419 many taxa might be more frequent due to the rise in sea level, which cause increased shelf island

420 formation. Parapatric processes are accelerated by the range expansions of lineages isolated in

421 the refugia and by the formation of potential suture zones.

422 Recent population of E. roumanicus in post-refugial area at Balkan Peninsula and adjacent

423 regions shows differentiation with particular subpopulation located in areas of interglacial

424 steppic refugia and glacial forest refugia. Detailed habitat model and past niche modelling will

425 be necessary to infer, which type of habitat was crucial for survival of E. roumanicus during

426 glacial periods. However, certain degree of admixture among particular clusters is obvious,

427 mirroring complex geomorphology and shape of geographical barriers, as well as altitudinal

428 heterogenetity within Balkan Peninsula. The situation might be further complicated by the fact,

429 that a mosaic of particular biomes often existed in refugia (Huntley \& Birks, 1983), increasing

430 the proportion of ecotones, and the biotas were often "disharmonious", i.e. particular ecosystems

431 often contain species that inhabit different habitats today (Tyrberg, 1991).

432

433

Acknowledgement 
434 We would like to thank all researchers and institutions which provided samples for this study (all

435 are listed in Supplemental information: Table S1). We thank to P. Matějů for help in laboratory.

436

437

438

439

440

441

442

443

444

445

446

447

448

449

450

451

452

453

454

455

456

457

458

459

460

461

462

463

464

465

\section{References}

Amori G, Hutterer R, Kryštufek B, Yigit N, Mitsain G, Palomo LJ. 2016. Erinaceus roumanicus. The IUCN Red List of Threatened Species 2016: e.T136344A22325720. DOI: 10.2305/IUCN.UK.2016-3.RLTS.T136344A22325720.en.

Anderson EC, Thompson E. 2002. A model-based method for identifying species hybrids using multilocus genetic data. Genetics 160: 1217-1229.

Balkenhol N, Cushman S, Storfer A, Waits L. 2015. Landscape genetics: concepts, methods, applications. Hoboken, New Jersey: Wiley-Blackwell.

Bandelt HJ, Forster P, Röhl A. 1999. Median-Joining Networks for Inferring Intraspecific Phylogenies. Molecular Biology and Evolution 16: 37-48.

Bannikova AA, Lebedev VS, Abramov AV, Rozhnov VV. 2014. Contrasting evolutionary history of hedgehogs and gymnures (Mammalia: Erinaceomorpha) as inferred from a multigene study. Biological Journal of Linnean Society 112: 499-519. DOI: $10.1111 /$ bij.12299.

Becher SA, Griffiths R. 1997. Isolation and characterization of six polymorphic microsatellite loci in the European hedgehog Erinaceus europaeus. Molecular Ecology 6: 89-90. DOI: 10.1046/j.1365-294X.1997.00159.x.

Belkhir K, Borsa P, Goudet J, Chikhi L, Bonhomme F. 1999. GENETIX v.4.05 logiciel sous Windows pour la génetique des populations. Available at http://kimura.univmontp2.fr/genetix/.

Blair C, Weigel DE, Balazik M, Keeley AT, Walker FM, Landguth E, Cushman S, Murphy M, Waits L, Balkenhol N. 2012. A simulation-based evaluation of methods for inferring linear barriers to gene flow. Molecular Ecology Resources 12: 822-33. DOI: 10.1111/j.1755-0998.2012.03151.x.

Bogdanov AS, Bannikova AA, Pirusskii YM, Formozov NA. 2009. The first genetic evidence of hybridization between West European and Northern White-breasted hedgehogs (Erinaceus europaeus and E. roumanicus) in Moscow region. Biological Bulletin 36: 647-651. DOI:10.1134/S106235900906017X. 
466

467

468

469

470

471

472

473

474

475

476

477

478

479

480

481

482

483

484

485

486

487

488

489

490

491

492

493

494

495

496

497

Bolfíková B, Hulva P. 2012. Microevolution of sympatry: landscape genetics of hedgehogs Erinaceus europaeus and E. roumanicus in Central Europe. Heredity 108: 248255. DOI: $10.1038 /$ hdy.2011.67.

Bolfíková B, Konečný A, Pfäffle M, Skuballa J. 2013. Population biology of establishment in New Zealand hedgehogs inferred from genetic and historical data: conflict or compromise? Molecular Ecology 22: 3709-3720. DOI: 10.1111/mec.12331.

Brewer S, Cheddadi R, de Beaulieu JL, Reille M. 2002. The spread of deciduous Quercus throughout Europe since the last glacial period. Forest Ecology and Management 156: $27-48$.

Chen C, Durand E, Forbes F, Francois O. 2007. Bayesian clustering algorithms ascertaining spatial population structure: a new computer program and a comparison study. Molecular Ecology Notes 7: 747-756. DOI: 10.1111/j.1471-8286.2007.01769.x.

Coyne JA, Orr HA. 2004. Speciation. Sunderland, Massachusetts: Sinauer Associates.

Drummond AJ, Rambaut A. 2007. BEAST: Bayesian evolutionary analysis by sampling trees. BMC Evolutionary Biology 7: 214. DOI: 10.1186/1471-2148-7-214.

Drummond AJ, Rambaut A, Shapiro B, Pybus OG. 2005. Bayesian Coalescent Inference of Past Population Dynamics from Molecular Sequences. Molecular Biology and Evolution 22: 1185-1192. DOI: 10.1093/molbev/msi103.

Durand E, Jay F, Gaggiotti OE, François O. 2009. Spatial inference of admixture proportions and secondary contact zones. Molecular Biology and Evolution 26: 19631973. DOI: $10.1093 / \mathrm{molbev} / \mathrm{msp} 106$.

Earl DA, VonHoldt BM. 2012. STRUCTURE HARVESTER: A website and program for visualizing STRUCTURE output and implementing the Evanno method. Conservation Genetic Resources 4: 359-361. DOI: 10.1007/s12686-011-9548-7.

ESRI ArcGIS Desktop: Release 10. 2014. Redlands, CA: Environmental Systems Research Institute.

Evanno G, Regnaut S, Goudet J. 2005. Detecting the number of clusters of individuals using the software STRUCTURE: A simulation study. Molecular Ecology 14: 261 1-2620. DOI: 10.1111/j.1365-294X.2005.02553.x.

Excoffier L, Ray N. 2008. Surfing during population expansions promotes genetic revolutions and structuration. Trends in Ecology \& Evolution 23: 347-351. DOI: 10.1016/j.tree.2008.04.004. 
498

499

500

501

502

503

504

505

506

507

508

509

510

511

512

513

514

515

516

517

518

519

520

521

522

523

524

525

526

527

528

529

530

531

Excoffier L, Foll M, Petit RJ. 2009. Genetic Consequences of Range Expansions. Annual Review of Ecology, Evolution, and Systematics 40: 481-501. DOI: 10.1146/annurev.ecolsys.39.110707.173414.

Fijarczyk A, Nadachowska K, Hofman S, Litvinchuk SN, Babik W, Stuglik M, Gollmann G, Choleva L, Cogălniceanu D, Vukov T, Džukić G, Szymura JM. 2011. Nuclear and mitochondrial phylogeography of the European fire-bellied toads Bombina bombina and Bombina variegata supports their independent histories. Molecular Ecology 20: 3381-3398. DOI: 10.1111/j.1365-294X.2011.05175.x.

Giagia-Athanasopoulou EB, Markakis G. 1996. Multivariate analysis of morphometric characters in the Eastern hedgehog Erinaceus concolor from Greece and adjacent areas. Zeitschrift Fuer Saeugetierkunde 61:1 29-139.

Goudet J. 1995. FSTAT (Version 1.2): A Computer Note Computer Program to Calculate F-Statistics. Journal of Heredity 86: 485-486.

Guillot G, Mortier F, Estoup A. 2005. GENELAND: A computer package for landscape genetics. Molecular Ecology Notes 5: 712-715. DOI: 10.1111/j.1471-8286.2005.01031.x.

Gvoždík V, Jandzik D, Lymberakis P, Jablonski D, Moravec J. 2010. Slow worm, Anguis fragilis (Reptilia: Anguidae) as a species complex: Genetic structure reveals deep divergences. Molecular Phylogenetics and Evolution 55: 460-472. DOI: 10.1016/j.ympev.2010.01.007.

Henderson M, Becher SA, Doncaster CP, Maclean N. 2000. Five new polymorphic microsatellite loci in the European hedgehog, Erinaceus europaeus. Molecular Ecology 9: 1949-1950. DOI: 10.1046/j.1365-294x.2000.01098-18.x.

Hewitt GM. 2000. The genetic legacy of the Quaternary ice ages. Nature 405: 907-913. DOI: $10.1038 / 35016000$.

Hewitt GM. 2001. Speciation, hybrid zones and phylogeography - Or seeing genes in space and time. Molecular Ecology 10: 537-549. DOI: 10.1046/j.1365294x.2001.01202.x.

Hulva P, Benda P, Hanák V, Evin A, Horáček I. 2007. New mitochondrial lineages within the Pipistrellus pipistrellus complex from Mediterranean Europe. Folia Zoologica 56: $378-388$.

Hulva P, Fornůsková A, Chudárková A, Evin A, Allegrini B, Benda P, Bryja J. 2010. Mechanisms of radiation in a bat group from the genus Pipistrellus inferred by phylogeography, demography and population genetics. Molecular Ecology 19: 54175431. DOI: 10.1111/j.1365-294X.2010.04899.x. 
532

533

534

535

536

537

538

539

540

541

542

543

544

545

546

547

548

549

550

551

552

553

554

555

556

557

558

559

560

561

562

563

564

565

Huntley B. 1999. Climatic change and reconstruction. Journal of Quarternary Science 14: 513-520. DOI: 10.1002/(SICI)1099-1417(199910)14:6<513::AID-JQS486>3.0.CO;2-E.

Huntley B, Birks HJB. 1983. An atlas of past and present pollen maps for Europe: 013000 years ago. Cambridge: Cambridge University Press.

Jarman MR. 1996. Human Influence in the Development Of the Cretan Mammalian Fauna. In: Reese DS, ed. Pleistocene and Holocene Fauna of Crete and Its First Settlers. Madison: Prehistoric Press.

Jensen AB. 2004. Overwintering of European hedgehogs Erinaceus europaeus in a Danish rural area. Acta Theriologica 49: 145-155. DOI: 10.1007/BF03192516.

Joger U, Fritz U, Guicking D, Kalyabina-Hauf S, Nagy ZT, Wink M. 2007. Phylogeography of western Palaearctic reptiles-Spatial and temporal speciation patterns. Zoologischer Anzeiger - A J. of Comp. Zool. 246: 293-313. DOI: 10.1016/j.jcz.2007.09.002.

Katoh K, Standley DM. 2013. MAFFT Multiple Sequence Alignment Software, Version 7: Improvements in Performance and Usability. Molecular Biology and Evolution 30: 772-780. DOI: $10.1093 / \mathrm{molbev} / \mathrm{mst} 010$.

Kearse M, Moir R, Wilson A, Stones-Havas S, Cheung M, Sturrock S, Buxton S, Cooper A, Markowitz S, Duran C, Thierer T, Ashton B, Meintjes P, Drummond A. (2012). Geneious Basic: An integrated and extendable desktop software platform for the organization and analysis of sequence data. Bioinformatics 28: 1647-1649. DOI: 10.1093/bioinformatics/bts199.

King RA, Ferris C. 1998. Chloroplast DNA phylogeography of Alnus glutinosa (L.) Gaertn. Molecular Ecology 7: 1151-1161. DOI: 10.1046/j.1365-294x.1998.00432.x.

Klopfstein S, Currat M, Excoffier L. 2006. The fate of mutations surfing on the wave of a range expansion. Molecular Biology and Evolution 23: 482-490. DOI: 10.1093/molbev/msj057.

Kryštufek B, Reed JM. 2004. Pattern and process in Balkan biodiversity - an overview. In: Griffiths HI, ed. Balkan Biodiversity: Pattern and Process in the European Hotspot. Springer Netherlands, 1-8. DOI: 10.1007/978-1-4020-2854-0_1.

Kryštufek B, Tvrtković N, Paunović M, Ozkan B. 2009. Size variation in the Northern white-breasted hedgehog Erinaceus roumanicus: Latitudinal cline and the island rule. Mammalia 73: 299-306. DOI: 10.1515/MAMM.2009.055.

Lax E, Strasser TF. 1992. Early Holocene Extinctions on Crete; the Search for the Cause. Journal of Meditteranean Archaeology 5: 203-224. DOI: 10.1558/jmea.v5i1.203. 
566

567

568

569

570

571

572

573

574

575

576

577

578

579

580

581

582

583

584

585

586

587

588

589

590

591

592

593

594

595

596

597

598

Mantel N. 1967. The detection of disease clustering and a generalized regression approach. Cancer Research 27: 209-220.

Miller MP. 2005. Alleles In Space (AIS): Computer software for the joint analysis of interindividual spatial and genetic information. Journal of Heredity 96: 722-724. DOI: 10.1093/jhered/esi119.

Posada D, Crandall K. 1998. MODELTEST: testing the model of DNA substitution. Bioinformatics 14: 817-818. DOI: 10.1093/bioinformatics/14.9.817.

Pritchard JK, Stephens M, Donnely PJ. 2000. Inference of population structure using multilocus genotype data. Genetics 155: 945-959.

Rambaut A, Suchard MA, Xie D, Drummond AJ. 2014. Tracer v1.6. Available from: http://beast.bio.ed.ac.uk/Tracer.

Ramírez-Soriano A, Ramos-Onsins SE, Rozas J, Calafell F, Navarro A. 2008.

Statistical power analysis of neutrality tests under demographic expansions, contractions and bottlenecks with recombination. Genetics 179: 555-567. DOI:

10.1534/genetics.107.083006.

Ramos-Onsins SE, Rozas J. 2002. Statistical properties of new neutrality tests against population growth. Molecular Biology and Evolution 19: 2092-2100. DOI:

10.1093/molbev/ms1052.

Rautio A, Valtonen A, Auttila M, Kunnasranta M. 2014. Nesting patterns of European hedgehogs (Erinaceus europaeus) under northern conditions. Acta Theriologica 59:173181. DOI: $10.1007 / \mathrm{s} 13364-013-0150-0$.

Rosenberg N. 2004. Distruct: a Program for the graphical display of population structure. Molecular Ecology Notes 4: 137-138. DOI: 10.1046/j.1471-8286.2003.00566.x.

Rousset F. 2008. GENEPOP'007: A complete re-implementation of the GENEPOP software for Windows and Linux. Molecular Ecology Resources 8: 103-106. DOI: 10.1111/j.1471-8286.2007.01931.x.

Rozas J, Sánchez-DelBarrio JC, Messeguer X, Rozas R. 2003. DnaSP, DNA polymorphism analyses by the coalescent and other methods. Bioinformatics 19: 24962497. DOI: 10.1093/bioinformatics/btg359.

Říčanová Š, Bryja J, Cosson JF, Gedeon C, Choleva L, Ambros M, Sedláček F. 2011. Depleted genetic variation of the European ground squirrel in Central Europe in both microsatellites and the major histocompatibility complex gene: implication for conservation. Conservation Genetics 12: 1115-1129. DOI: 10.1007/s10592-011-0213-1. 
599

600

601

602

603

604

605

606

607

608

609

610

611

612

613

614

615

616

617

618

619

620

621

622

623

624

625

626

627

628

629

Santucci F, Emerson BC, Hewitt GM. 1998. Mitochondrial DNA phylogeography of European hedgehogs. Molecular Ecology 7: 1163-1172. DOI: 10.1046/j.1365294x.1998.00436.x.

Schaschl H, Lymberakis P, Suchentruck F. 2002. On allozyme and cyt-b gene characteristics of Cretan hedgehogs, Erinaceus consolor nesiotes Bate, 1906. Mammalian Biology 67: 257-267. DOI:10.1078/1616-5047-00040.

Schule W. 1993. Mammals, vegetation and the initial human settlement of the Mediterranean islands: a palaeoecological approach. Journal of Biogeography 20: 399412. DOI: $10.2307 / 2845588$.

Seddon JM, Santucci F, Reeve NJ, Hewitt GM. 2001. DNA footprints of European hedgehogs, Erinaceus europaeus and E. concolor: Pleistocene refugia, postglacial expansion and colonization routes. Molecular Ecology 10: 2187-2198. DOI: 10.1046/j.0962-1083.2001.01357.x.

Seddon JM, Santucci F, Reeve N, Hewitt GM. 2002. Caucasus Mountains divide postulated postglacial colonization routes in the white-breasted hedgehog, Erinaceus concolor. Journal of Evolutionary Biology 15: 463-467. DOI: 10.1046/j.14209101.2002.00408.x.

Stewart JR, Lister AM, Barnes I, Dalén L. 2010. Refugia revisited: individualistic responses of species in space and time. Proceedings of the Royal Society 277: 661-6. DOI: 10.1098/rspb.2009.1272.

Tyrberg T. 1991. Arctic, montane and steppe birds as glacial relicts in the west palearctic. Ornithologische Verhandlungen 25: 29-49.

Tzedakis PC. 2004. The Balkans as prime glacial refugial territory of European temperate trees. In: Griffiths HI, ed. Balkan Biodiversity: Pattern and Process in the European Hotspot. Springer Netherlands, 1-8. DOI: 10.1007/978-1-4020-2854-0_1.

Van der Geer A, Lyras G, de Vos J, Dermitzakis M. 2010. Evolution of Island Mammals. London: Wiley-Blackwell.

Van Oosterhout C, Hutchinson WF, Wills DPM, Shipley P. 2004. MICROCHECKER: S ftware for identifying and correcting genotyping errors in microsatellite data. Molecular Ecology Notes 4: 535-538. DOI: 10.1111/j.1471-8286.2004.00684.x. 


\section{Table $\mathbf{1}$ (on next page)}

The descriptive statistics of microsatellite genetic diversity in seven populations of Erinaceus roumanicus, which were recognised by the Bayesian clustering analysis using Structure.

Number of alleles $\left(N_{\mathrm{a}}\right)$, allelic richness $\left(A_{\mathrm{R}}\right)$, expected heterozygosity $\left(H_{\mathrm{E}}\right)$, observed heterozygosity $\left(H_{0}\right)$, inbreeding coefficient $\left(F_{15}\right)$ are given for each population. 


\begin{tabular}{llllll}
\hline & $N_{\mathrm{a}}$ & $A_{\mathrm{R}}$ & $H_{\mathrm{E}}$ & $H_{\mathrm{O}}$ & $F_{\mathrm{IS}}$ \\
\hline Czech Republic & 7 & 6.187 & 0.7120 & 0.6151 & 0.134 \\
Slovakia, Hungary & 9 & 7.318 & 0.7032 & 0.6291 & 0.097 \\
Romania & 9 & 6.575 & 0.7521 & 0.6171 & 0.242 \\
Slovenia & 8 & 6.317 & 0.6844 & 0.6071 & 0.102 \\
Croatia, Bosnia and Herzegovina & 9 & 7.045 & 0.7125 & 0.6442 & 0.114 \\
Bulgaria, Greece, Macedonia, Serbia, Montenegro & 10 & 7.912 & 0.7628 & 0.6923 & 0.102 \\
Crete & 6 & 4.994 & 0.5243 & 0.4292 & 0.167
\end{tabular}

1 


\section{Table 2 (on next page)}

The summary statistics of the partial control region of mitochondrial DNA in six populations of Erinaceus roumanicus, which were recognised by Bayesian analysis using Geneland.

Colours in bracelets correspond to colours used in Fig. 5c. Number of individuals ( $N$ ), number of haplotypes $\left(N_{\mathrm{h}}\right)$, haplotype diversity $\left(H_{\mathrm{d}}\right)$, number of polymorphic sites $\left(N_{\mathrm{p}}\right)$, nucleotide polymorphism $(\pi)$, Tajima's $D(D)$, Fu's $F s\left(F_{\mathrm{s}}\right)$ and $R^{2}$ are given for each population and for whole dataset. The significant values tests are shown with asterisks $\left(* p<0.05,{ }^{* *} p<0.01\right.$, $* * * p<0.001)$ 


\begin{tabular}{lccllllll}
\hline & $n$ & $N_{\mathrm{h}}$ & $H_{\mathrm{d}}$ & $N_{\mathrm{p}}$ & $\pi$ & $D$ & $R^{2}$ & $F_{\mathrm{S}}$ \\
\hline Central Europe (orange) & 58 & 6 & 0.3134 & 10 & 0.00204 & -0.92848 & 0.0688 & -0.561 \\
Carpathians (yellow) & 41 & 10 & 0.8269 & 9 & 0.00292 & -0.81891 & 0.0874 & $-2.779^{*}$ \\
North Balcan (pink) & 63 & 15 & 0.6912 & 17 & 0.00272 & -1.35223 & 0.0534 & $-7.052^{* * *}$ \\
Black sea cost (violet) & 23 & 9 & 0.7787 & 14 & 0.00548 & -1.25805 & $0.0817^{*}$ & -2.731 \\
Dinarids (green) & 59 & 17 & 0.8954 & 19 & 0.00568 & -0.90052 & 0.0730 & $-5.470^{* *}$ \\
South Balkan (blue) & 52 & 11 & 0.3808 & 18 & 0.00229 & $-1.82115^{*}$ & $0.0492^{*}$ & $-5.937^{*}$ \\
\cline { 2 - 8 } & 296 & 53 & 0.9185 & 38 & 0.00644 & -1.38337 & 0.0415 & $-3.638^{* * *}$
\end{tabular}




\section{Figure 1 (on next page)}

Sampling localities for the 314 samples of the Northern White-breasted Hedgehog (Erinaceus roumanicus) in central Europe and the Balkan region.

Each sampled individual is represented by a pink dot. The distribution map of the species is shown in the smaller square. Map was done using ArcGIS (ESRI 2017) using publicly available layers (Bathymetry - EMODnet, Administrative areas - GADM database, Elevation - WorldClim database, Rivers - EEA hydrographic data set). Inset of the figure is based on an IUCN distribution map of species (Amori et al., 2016) edited for the purposes of this article in Photoshop CS3 (Adobe). 


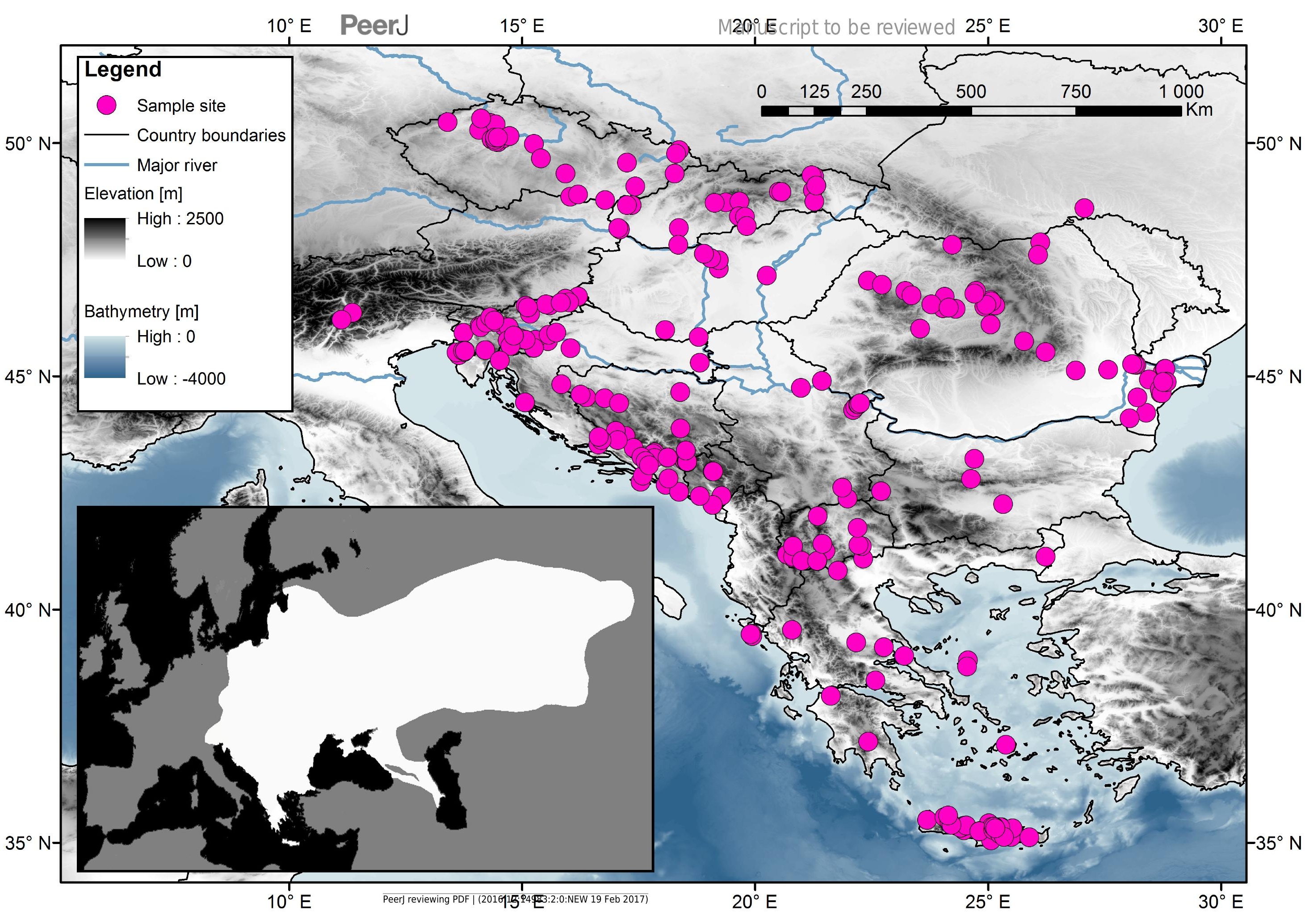


Figure 2

Structuring of the nuclear data

(a) Population assignment using Bayesian clustering analysis in Structure for the 260

Erinaceus roumanicus samples in Central Europe and the Balkan region. The results are shown for $K=2$ to $K=7$. The highest $\Delta K$ was for $K=3$, and the second highest $\Delta K$ was for $K$ = 7. (b) Geographical cluster assignments implemented by TESS. The results display five colours for $\mathrm{Kmax}=6$.

a)

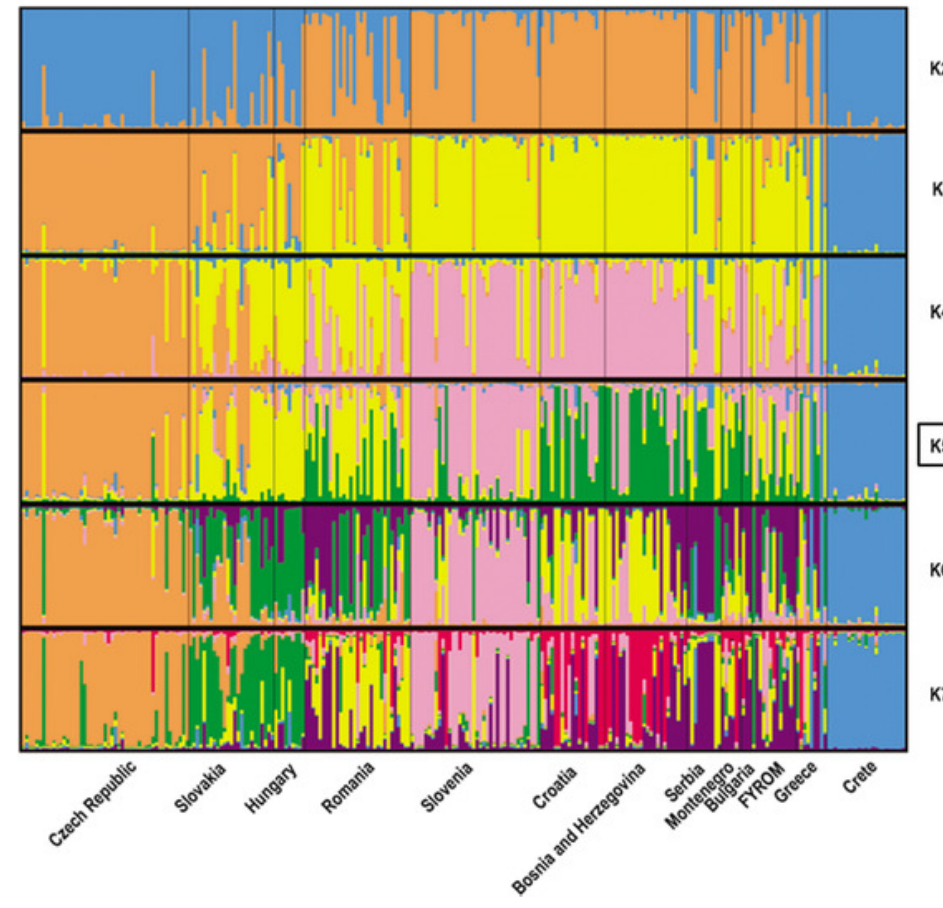

b)

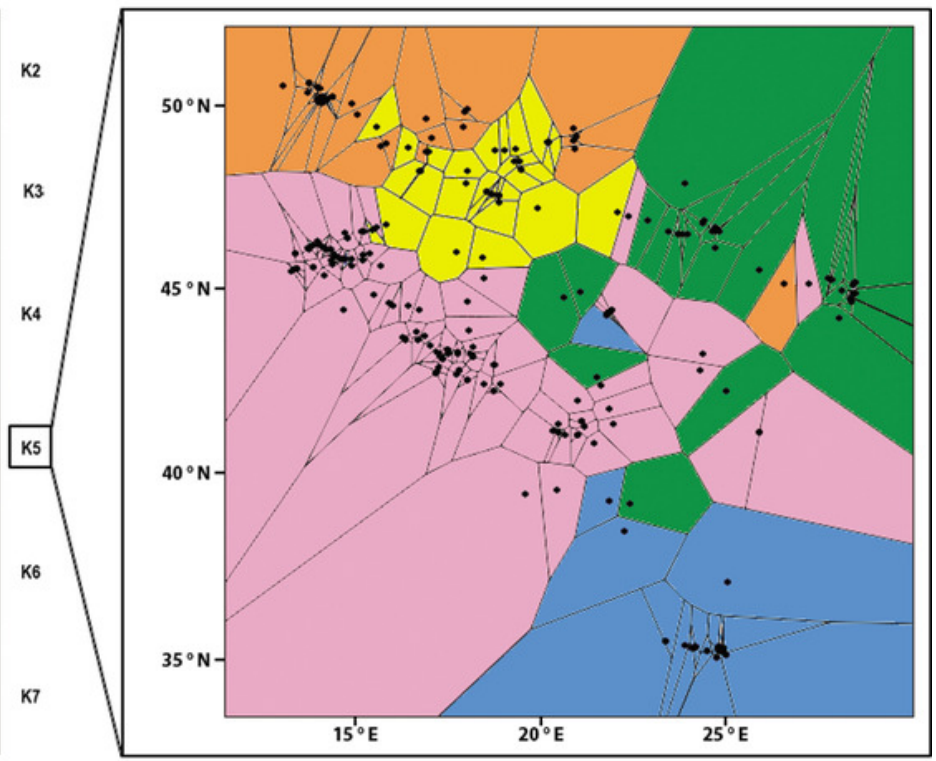


Figure 3 (on next page)

Median-joining network of the mitochondrial control region haplotypes for 296 Erinaceus roumanicus samples.

Haplotypes are represented by circles, which are proportional to the haplotype frequency. The hypothesized haplotypes are represented by red dots. Colour codes are used according to the population assignments of the samples using mtDNA data from the Geneland analysis (see Fig. 5c or Supporting information: Table S1). Lines between nodes represent a nucleotide changes. 


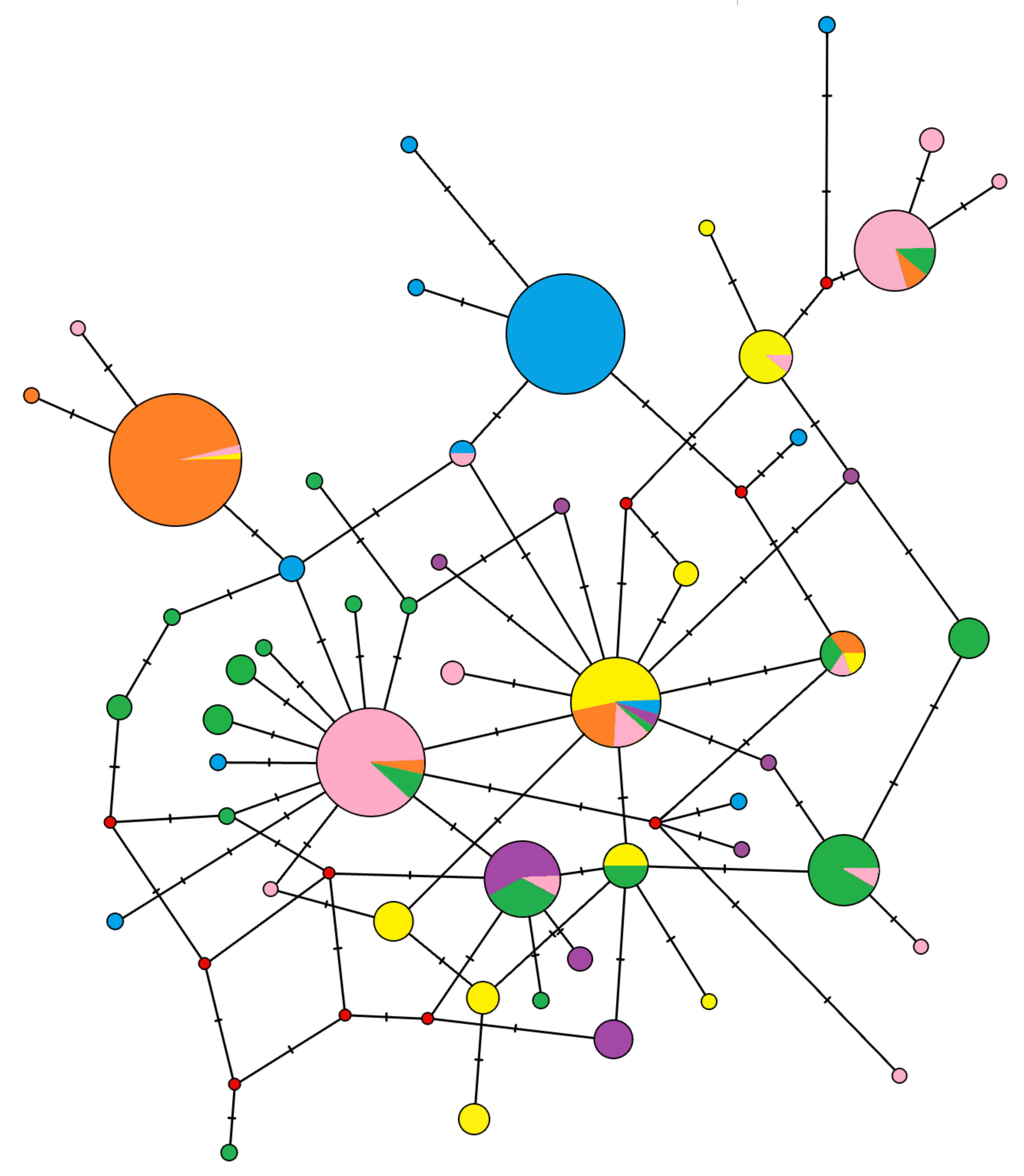




\section{Figure 4}

Bayesian skyline plot based on mtDNA of 296 Erinaceus roumanicus samples.

The $\mathrm{X}$ axis represents the time in mutation units per nucleotide position. The $\mathrm{Y}$ axis represents a correlate of the population size $(\mathrm{Ne})$. The black line shows the median of the $\mathrm{Ne}$ estimation, and the $95 \%$ confidence intervals are indicated by the blue areas.

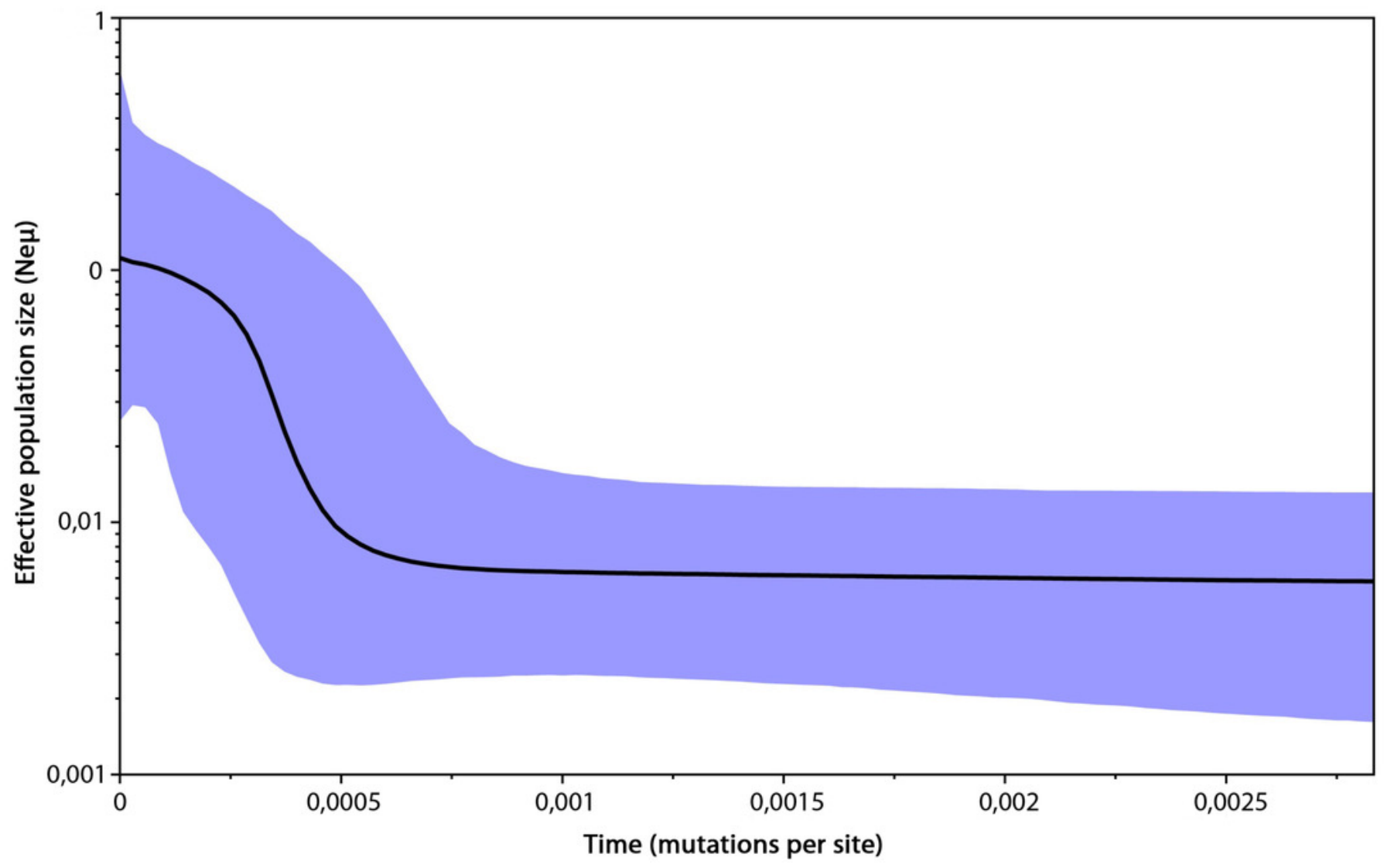




\section{Figure 5}

Genetic landscape shape interpolation analysis.

Genetic landscape shape interpolation analysis based on variation of (a) the control region of mtDNA using 296 Erinaceus roumanicus samples and (b) nine nuclear microsatellite loci using $260 \mathrm{E}$. roumanicus samples. The $X$ and $Y$ axes reflect the geographic coordinates within the study area, while the $Z$ axis represents the average genetic distances between the analysed samples. The Bayesian landscape genetic analysis using Geneland illustrates the spatial distribution of the populations using (c) the control region of mtDNA and (d) nine nuclear microsatellite loci. Figure was done using publicly available outlines ( https://CRAN.R-project.org/ package=rworldmap ) and edited in Photoshop CS3 (Adobe). 
a)

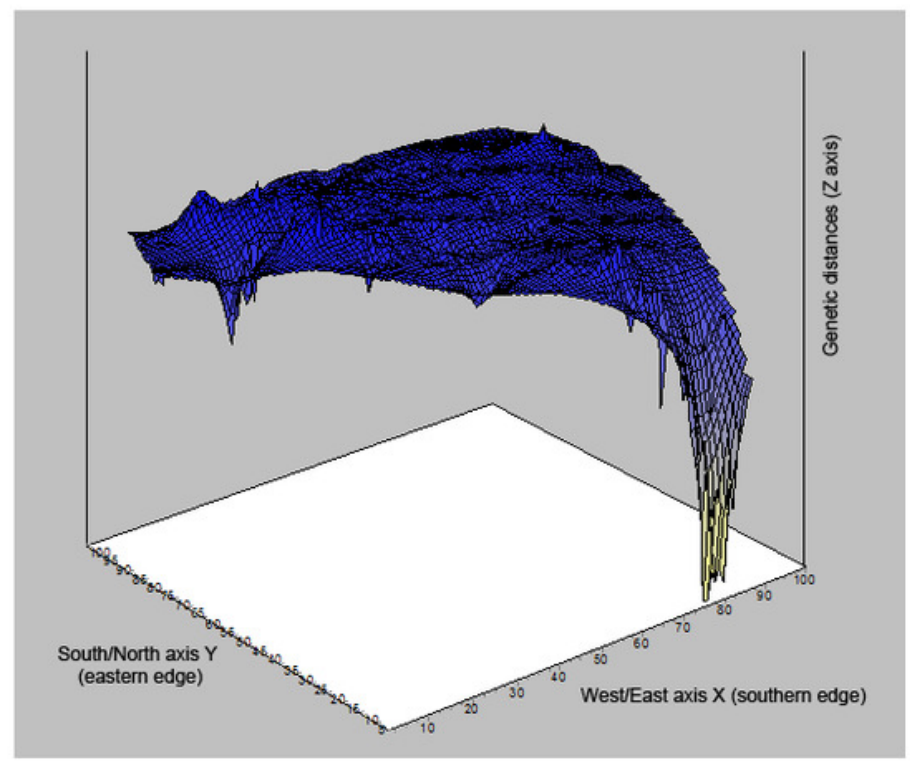

c)

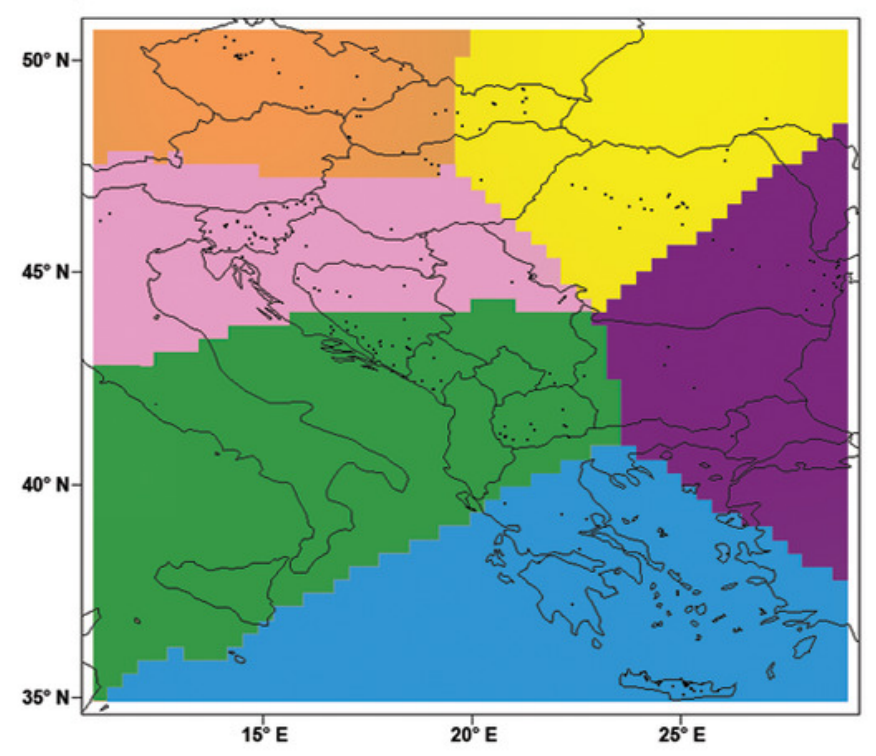

b)

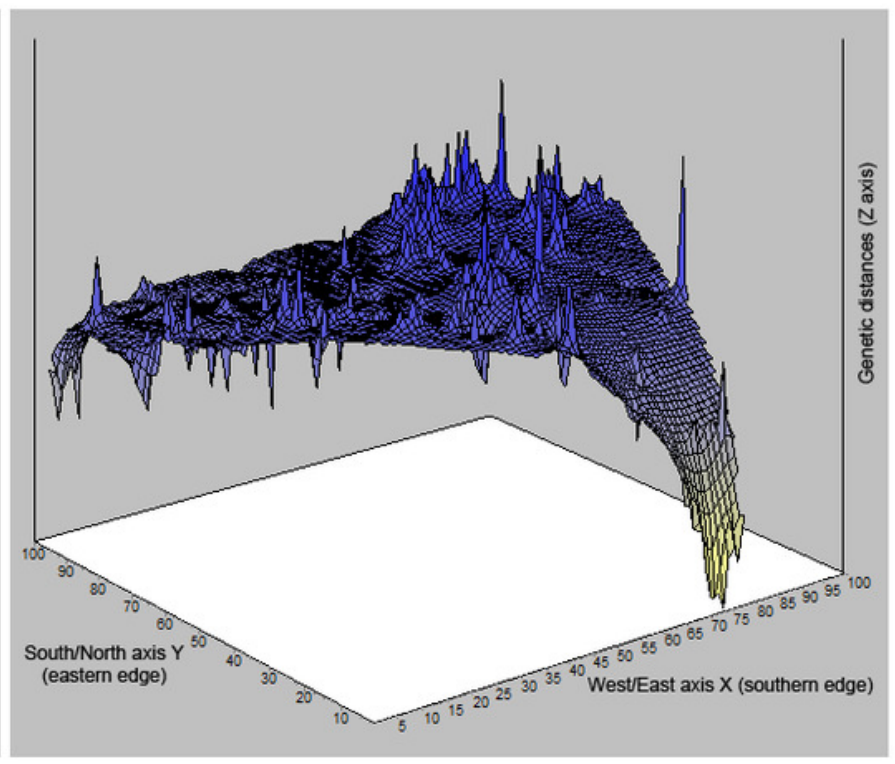

d)

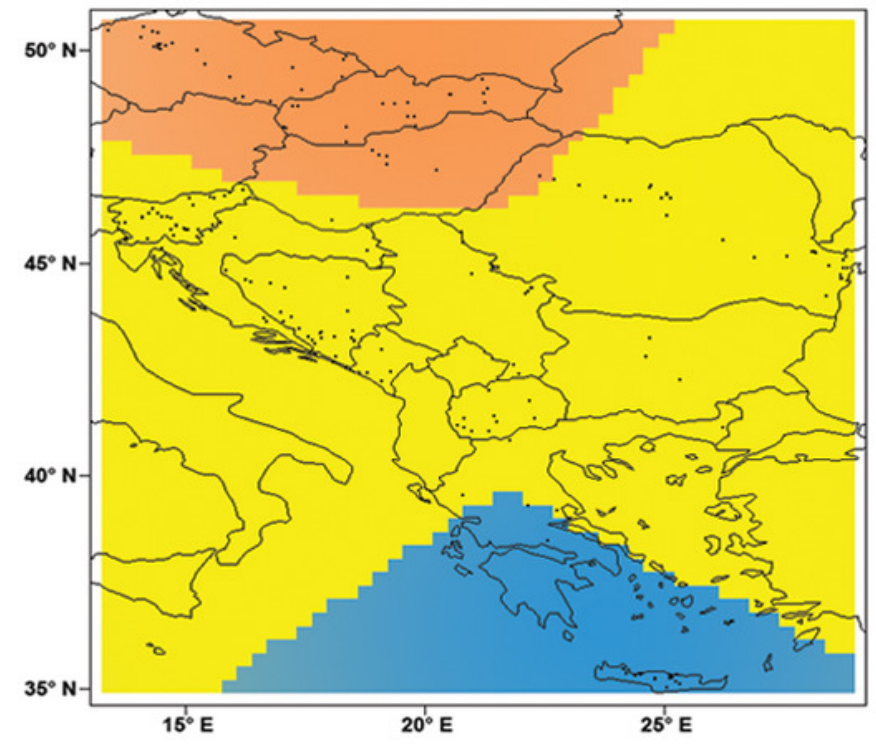

